\title{
Effect of Etching and Light-Curing Time on the Shear Bond Strength of a Resin-Modified Glass Ionomer Cement
}

\author{
Ivan Toshio MARUO 1 \\ Juliana GODOY-BEZERRA2 \\ Armando Yukio SAGA ${ }^{1}$ \\ Orlando Motohiro TANAKA ${ }^{1}$ \\ Hiroshi MARUO ${ }^{1}$ \\ Elisa Souza CAMARGO ${ }^{1}$ \\ ${ }^{1}$ Pontifical Catholic University of Paraná, Curitiba, PR, Brazil \\ ${ }^{2}$ University of Pernambuco, Recife, PE, Brazil
}

\begin{abstract}
The aim of this study was to assess the influence of etching and light-curing time on the shear bond strength (SBS) and adhesive remnant index (ARI) of a resin-modified glass ionomer cement (RMGIC) upon debonding of orthodontic brackets. Sixty-eight bovine permanent incisors were obtained and embedded in acrylic resin. Edgewise metallic brackets were bonded to the teeth with Fuji Ortho LC RMGIC. The specimens were randomly assigned to 4 groups, using the following etching and light-curing times: G1: 10\% polyacrylic acid and $40 \mathrm{~s}$ (control); G2: 37\% phosphoric acid and $40 \mathrm{~s}$; G3: $10 \%$ polyacrylic acid and $50 \mathrm{~s}$; and G4: $37 \%$ phosphoric acid and $50 \mathrm{~s}$. Shear test was performed at $0.5 \mathrm{~mm} / \mathrm{min}$ and the ARI was assessed. G2 (3.6 $\pm 0.98 \mathrm{MPa})$ presented significantly higher $(p<0.05)$ SBS than G1 $(2.76 \pm 0.86 \mathrm{MPa})$ and G4 $(2.86 \pm 0.68 \mathrm{MPa})$, and there was no statistically significant difference $(\mathrm{p}>0.05)$ between G2 and G3 (2.94 $\pm 0.67 \mathrm{MPa})$. ARI presented prevalence of scores 2 and 3 in all groups. RMGIC SBS enhanced with $37 \%$ phosphoric acid etching and $40 \mathrm{~s}$ light-curing time, but this did not occur when the light-curing time was increased, regardless of the acid used. RMGIC presented prevalence of failures at the adhesive/bracket interface.
\end{abstract}

Key Words: orthodontics, bonding, resin-modified glass ionomer cement.

\section{INTRODUCTION}

Since etching was introduced by Buonocore (1) and Newman (2) began direct bonding of orthodontic attachments, composite resin has been the most commonly used bonding system in Orthodontics due to its higher bond strength compared to other materials (3). However, composite resin presents some disadvantages such as the lack of fluoride protection, which increases the risk of white spot formation close to bonded orthodontic brackets (4), the need of a completely dry operative field throughout the bonding procedure (5), and the possibility of enamel damage during debonding (3). All these shortcomings led to the introduction of fluoride-releasing composite resins for clinical purposes. However, the use of these materials were later discontinued either due to an increased incidence of bond failure or because composite resin released fluoride in very small amounts $(6,7)$.

For this reason, the use of other materials in Orthodontics has been proposed, such as glass ionomer cements (GICs) (6). The favorable characteristics of GICs include continuous fluoride release, acting as a reservoir of fluoride absorbed from toothpastes and oral rinses (6), both inhibiting bacterial acid metabolism and activity (9) and minimizing enamel decalcification (6); biocompatibility; chemical bonding both to enamel and dentin that makes etching treatment of enamel unnecessary (3); effective bonding in a moist environment without the need for an additional bonding agent layer; and higher frequency of bond failure either at the adhesive-bracket interface or cohesive fracture in 
the material, avoiding damage to enamel (9). From an orthodontic perspective, one of the disadvantages of GICs is their lower bonding strength to brackets when compared to composite resins $(3,8,9)$.

Hybrid GICs or resin-modified GICs (RMGICs) have been developed in an attempt to improve the chemical and physical properties of the conventional GICs, combining their properties with those of composite resins (7). However, while having higher bond strength than the conventional formulations, RMGICs still have lower bond strength than composite resins, which have stimulated the development of different bonding protocols in order to improve it. There are some factors that can potentially contribute to the bond strength between enamel and orthodontic bracket, including type of enamel conditioner $(3,10)$, length of etching time (10), bracket base design and material, oral environment, as well as clinician skill (7).

The manufacturer's instructions of RMGIC include use of $10 \%$ polyacrylic acid enamel conditioner and 40 s light-curing time. Due to its higher frequency of bond failures than composite resins, some authors have been studying different bonding protocols in order to enhance its initial bond strength, such as $37 \%$ phosphoric acid enamel etching (3) and other conditioners (9) before the RMGIC application, as well as additional light-curing times of 5 and $10 \mathrm{~s}(7)$.

As orthodontists seek to use materials that both minimize decalcification problems and have acceptable bond strengths, the aim of this study was to evaluate the effects of etching and light-curing time on the RMGIC shear bond strength (SBS) and Adhesive Remnant Index (ARI) upon debonding of orthodontic brackets.

\section{MATERIAL AND METHODS}

After research project approval by the Research Ethics Committee for Animal Research of the Pontifical Catholic University of Paraná, Brazil (protocol number 20/04/CEPA-PUCPR), 68 freshly extracted bovine mandibular incisors were collected, had the roots scaled for removal of surface-adhered soft tissues, and were stored in a $0.1 \%$ thymol solution for 15 days. Thereafter, the roots were cut in the middle third, the pulps were removed, and the specimens were stored in distilled water at room temperature.

As described by Godoy-Bezerra et al. (5), in order to achieve a standardized bonding and shear testing, specimen preparation sought to obtain a regular buccal surface perpendicular to the horizontal plane. This was made by delimiting each tooth buccal central area, pressing it against a smooth glass surface, embedding it in acrylic resin and wet grounding it until a $25 \mathrm{~mm}^{2}$ flat enamel surface was obtained. After these procedures, the roots were embedded in acrylic resin in a PVC metal mould ( $2.5 \mathrm{~cm}$ diameter and $2 \mathrm{~cm}$ deep), using an L-shaped acrylic device.

The specimens were randomly assigned to 4 groups $(n=17)$. G1 was the control group. Each tooth was cleaned and polished with non-fluoridated pumice and rubber cups for $10 \mathrm{~s}$, each cup being changed after use in 5 teeth. Enamel etching was done as follows: G1 and G3: following manufacturer's instructions, $10 \%$ polyacrylic acid was applied for $20 \mathrm{~s}$, thoroughly rinsed with water for $20 \mathrm{~s}$, and dried for the same time. G2 and G4: 37\% phosphoric acid was applied for 20 $\mathrm{s}$, thoroughly rinsed with water for $20 \mathrm{~s}$, and dried for the same time.

In all groups, stainless steel mandibular incisor .022 " x .030" edgewise brackets (Morelli ${ }^{\circledR}$, Sorocaba, SP, Brazil) were used. During the bonding procedure, slot was maintained perpendicular to horizontal plane by an acrylic guiding device with a central .0215 " $\mathrm{x} .0280$ " wire, in such a way that during the SBS test the "wing deformity" factor would be minimized.

RMGIC Fuji Ortho LC (GC America, Chicago, IL) was mixed following the manufacturer's instructions and placed on the bracket base. Then, each bracket was placed and pressed onto tooth surface with $400 \mathrm{gf}$ load using a dynamometer to standardize film thickness. Excess cement was removed with a sharp scalpel.

Bonding material was light-cured for a total length of $40 \mathrm{~s}$ in $\mathrm{G} 1$ and $\mathrm{G} 2$, being $10 \mathrm{~s}$ in the mesial, distal, occlusal and gingival directions; and for a total length of $50 \mathrm{~s}$ in G3 and G4, bonding material was initially light-cured for $10 \mathrm{~s}$ and then proceeding as G1 and G2. The irradiance of the light-curing unit (Optilux 500, Demetron Research, Danbury, CT, USA) was checked before each bonding procedure to ensure a $540 \pm 20$ $\mathrm{mW} / \mathrm{cm}^{2}$ output of light.

After $24 \mathrm{~h}$, an occlusogingival load was applied to the bracket in a universal testing machine (EMIC DL 500, São José dos Pinhais, PR, Brazil) at a crosshead speed of $0.5 \mathrm{~mm} / \mathrm{min}$ producing a shear force for the debonding procedure. A computer connected to this machine recorded SBS in MPa, considering bracket area of $12 \mathrm{~mm}^{2}$.

After bracket removal, teeth and brackets 
were examined under a $\times 10$ magnification using a stereomicroscope (BX 60M; Olympus, Tokyo, Japan). The simplified ARI (11) was scored as follows: 0: no adhesive left on the tooth; 1 : less than half of adhesive left on the tooth; 2: more than half of adhesive left on the tooth; and 3: all adhesive left on the tooth, with distinct bracket mesh impression. According to Flores et al. (3), the possibility of all adhesive remain both on tooth and on bracket, i.e., a cohesive fracture, was included in score 3. ARI indicates that bond failure site occurred either at the enamel/adhesive interface (scores 0 and 1) or at the adhesive/bracket interface (scores 2 and 3 ).

The Kolmogorov-Smirnov and Levene tests were used to confirm the data normality and homogeneity, respectively. Then, two-way ANOVA (etching agent and light-curing time) and Tukey's HSD test were used to compare the SBS means among the groups. The prevalence of ARI scores among the groups was compared by the Kruskal-Wallis test. For both SBS and ARI data, a significance level of 0.05 was set for identifying any statistically significant differences.

\section{RESULTS}

\section{SBS}

There was no statistically significant difference ( $>0.05$ ) among the groups when the etching agent was considered, independently of the light-curing time and when light-curing time was considered regardless of the etching agent. However, when etching agent and light-curing time were associated, statistically significant difference $(p<0.05)$ was observed in at least one group.

G2, which used $37 \%$ phosphoric acid and $40 \mathrm{~s}$ light-curing time, presented significantly higher SBS than G1 and G4 $(p<0.05)$. G2 also presented higher values than G3, although it was not statistically significant $(p>0.05)$. There was no statistically significant difference

Table 1. Shear bond strength means (in $\mathrm{MPa}$ ) and standard deviations, according to etching agent and light-curing time.

\begin{tabular}{lc}
\hline Acids x Times & Mean (SD) \\
\hline $10 \%$ polyacrylic acid $+40 \mathrm{~s}(\mathrm{G} 1)$ & $2.76^{\mathrm{a}}(0.83)$ \\
$37 \%$ Phosphoric acid $+40 \mathrm{~s}(\mathrm{G} 2)$ & $3.60^{\mathrm{b}}(0.98)$ \\
$10 \%$ polyacrylic acid $+50 \mathrm{~s}(\mathrm{G} 3)$ & $2.94^{\mathrm{a}, \mathrm{b}}(0.67)$ \\
$37 \%$ Phosphoric acid $+50 \mathrm{~s}(\mathrm{G} 4)$ & $2.86^{\mathrm{a}}(0.68)$ \\
\hline
\end{tabular}

Same letters indicate no statistically significant difference $(\mathrm{p}>0.05)$.
( $>0.05$ ) among G1, G3 and G4 (Table 1).

ARI

The ARI values are shown in Table 2. All groups presented prevalence of scores 2 and 3 (G1 - 64.70\%; G2 - 100.00\%; G3 - 76.48\%; and G4 - 94.12\%), i. e., bond failure occurred at the adhesive/bracket interface. There was no statistically significant difference $(p>0.05)$ among G1, G3 and G4, and only G2 presented constant 3 scores, differing significantly from the others $(p<0.05)$.

\section{DISCUSSION}

Methods of increasing RMGIC SBS are sought due to its higher biocompatibility when compared to composite resins. However, a lack of standardization in the methods used for bond strength testing in Orthodontics makes comparison of different studies difficult and often impossible (12). Studies are different in direction of force used in mechanical testing (9), sample storage time before mechanical testing $(3,13)$, cross-head speed $(3,8,9,13)$, tested materials $(9,13)$ and tooth type $(3,7,8,10,13)$. For this reason, the absolute values of these studies cannot be compared.

In the same way as demonstrated by GodoyBezerra et al. (5), the present research did not attempt to reproduce human oral environment or to evaluate whether RMGIC present acceptable clinical bond strength. For these purposes, in vivo studies $(14,15)$ were designed. On the contrary, as an in vitro study, the present research was designed to standardize the maximum amount of variables possible in order to understand and explain all events involved in the influence of etching and light-curing time on SBS.

Table 2. Adhesive Remnant Index (ARI) scores in the groups.

\begin{tabular}{lcccc}
\hline \multirow{2}{*}{ Groups } & \multicolumn{4}{c}{ ARI (\%) } \\
\cline { 2 - 5 } & 0 & 1 & 2 & 3 \\
\hline G1 & 17.65 & 17.65 & 5.88 & 58.82 \\
G2 & 0 & 0 & 0 & 100.00 \\
G3 & 11.76 & 11.76 & 0 & 76.48 \\
G4 & 5.88 & 0 & 0 & 94.12 \\
\hline
\end{tabular}

ARI $0=$ no adhesive left on the tooth; ARI $1=$ less than half of adhesive left on the tooth; ARI 2 = more than half of adhesive left on the tooth; ARI 3 = all adhesive left on the tooth, with distinct bracket mesh impression. 
Bovine enamel is commonly used in bonding studies because of the advances in dental health and conservative dentistry as well as the limits in the access to human teeth $(16,17)$. Relatively lower SBS values found in this study can be justified by the fact that bovine teeth present weaker bond strength than human teeth (16). Clinically reasonable values cited by Reynolds (18) cannot be accepted as a reference because his study was a literature review and there is no evidence-based arguments for the 5 to $8 \mathrm{MPa}$ values.

Although there was great variability within each group, statistical analysis showed that all groups presented normality and homogeneity, which permitted the use of parametric statistical tests.

Valente et al. (10) affirmed that RMGICs still need etching to enhance their bond strength and demonstrated that using phosphoric acid for $15 \mathrm{~s}$ would be sufficient to promote reasonable bond strength. Based on these results, the present research used $37 \%$ phosphoric acid etching for $20 \mathrm{~s}$, in the same way as Flores et al. (3), to permit direct comparison with $10 \%$ polyacrylic acid, whose manufacturer recommends $20 \mathrm{~s}$ of etching time.

The present study demonstrated that $37 \%$ phosphoric acid with 40 s light-curing time was efficient in enhancing RMGIC SBS in comparison to $10 \%$ polyacrylic acid. This is in accordance with some studies $(3,13)$ and in contrast with another one $(10)$.

Bond strength increase using 37\% phosphoric acid is explained by the production of qualitatively rougher enamel in comparison to the enamel surface produced by $10 \%$ polyacrylic acid (14). Nonetheless, in the present study, phosphoric acid did not increase bond strength in $50 \mathrm{~s}$ light cure time.

The fact that longer light-curing time exposure did not enhance bond strength, which is demonstrated by the non-significant difference between control and $50 \mathrm{~s}$ light-curing time groups (using either 10\% polyacrylic or $37 \%$ phosphoric acid) differs from the findings of a previous study (7), which found bond strength increase when using 45 and $50 \mathrm{~s}$ light-curing times, without difference between these groups, but lower standard deviation in a $50 \mathrm{~s}$ light-curing time. However, those authors (7) presented high standard deviations. In the present research, on the contrary, all groups presented normality and homogeneity in bond values, which permitted the use of parametric statistical tests.

At first, the difference from the results of Bishara et al. (7) could be explained by differences in methodologies, mainly in the type of enamel used.
According to Lopes et al. (17), human and bovine equivalence depends on the bond system used. However, as $37 \%$ phosphoric acid increased bond strength when used with $40 \mathrm{~s}$ light-curing time, the explanation for this divergence must be in chemical composition of the RMGIC.

RMGIC main component is a fine fluoroaluminum glass powder, the liquid being polyacrylic acid, water and a monomer as an activator. The resin compound is a mixture of three monomers, mainly 2-hydroxyethyl methacrylate (HEMA), which enhances the polymerization reaction (14). As Mount et al. (19) affirm, from the start of RMGIC mixing, there is the conventional acid/base reaction with the polyalkenoic acid attacking the surface of the glass particles and releasing calcium and aluminium ions to form the matrix in a little slower manner than it would have been in a conventional GIC because the HEMA has replaced some of the normal water content and water is an essential component of the acid/base reaction. At the same time because of the incorporation of traces of camphorquinone and a tertiary amine in the formula, irradiation will initiate polymerization of the HEMA and this will be complete in less than $1 \mathrm{~min}$. This reaction is quite separate from the acid/base reaction, but a high degree of crosslinking will occur between the two matrices as the acid/base reaction continues. Considering all these chemical reactions, HEMA, which is highly hydrophilic, may lead to water uptake over time and a reduction in wear resistance, or there is the risk of phase separation of matrices, possibly leading to cement breakdown.

Longer light-curing time means more resin monomer conversion. Therefore, it was expected that, due to its resin portion, RMGIC SBS would increase. This is why the explanation for the lack of bond strength enhance should be attributed to the RMGIC ionomer portion. Criteria, such as surface roughness, particle-size distribution, incorporation of air bubbles, porosities and water absorption, are important parameters and influence the mechanical properties of materials (20).

As Iazzetti et al. (20) have demonstrated, glass ionomer produces cracking easily, especially when dehydrated, because, in this case, numerous areas of porosity appear, providing a pathway for cracks to spread through the material, decreasing its mechanical strength. The longer light-time used in the present research may have acted, dehydrating cement and decreasing its SBS. Because of that, even $37 \%$ acid phosphoric etching was not able to enhance RMGIC SBS. 
Regarding ARI, in all groups, the great majority of bond failure occurred at the adhesive/bracket interface. When $37 \%$ phosphoric acid was used, almost all failures occurred in this manner. If the results of this in vitro study repeat under in vivo conditions, it would represent a clinical advantage in using pretreatment with phosphoric acid before use of RMGICs because it would mean no enamel damage during debonding. Furthermore, in case of accidental bracket debonding, cement remnant would remain attached to conditioned tooth surface, still permitting fluoride releasing (3).

As an in vitro research, the results of this study must be carefully analyzed and clinical studies are needed for confirmation of findings.

The following conclusions can be drawn: 1) $37 \%$ phosphoric acid etching was effective in increasing RMGIC SBS, when 40 s of light-curing time was used;2) Longer light-curing time was not effective in increasing RMGIC SBS, independently of the acid etchant, and compromised the possible positive effect of $37 \%$ phosphoric acid etching; and 3) There was prevalence of bond failure at the adhesive/bracket interface, independently of the etching and light-curing time.

\section{RESUMO}

O objetivo desta pesquisa foi avaliar a influência do condicionamento ácido e do tempo de fotopolimerização na Resistência Adesiva (RA) e no Índice de Adesivo Remanescente (IAR) do Cimento Ionômero de Vidro Modificado por Resina (CIVMR). Sessenta e oito incisivos permanentes de bovinos foram obtidos e incluídos em resina acrílica. Bráquetes metálicos edgewise foram colados nesses corpos de prova com o CIVMR Fuji Ortho. A amostra foi dividida em 4 grupos, utilizando os seguintes condicionamentos ácidos e tempos de fotopolimerização: G1Ácido poliacrílico a 10\% e $40 \mathrm{~s}$ (controle); G2- Ácido fosfórico a $37 \%$ e 40 s; G3- Ácido poliacrílico a $10 \%$ e 50 s; e G4- Ácido fosfórico a $37 \%$ e $50 \mathrm{~s}$. O teste de cisalhamento foi realizado a $0,5 \mathrm{~mm} / \mathrm{min}$ e o IAR avaliado. O G2 (3,6 $\pm 0,98 \mathrm{MPa})$ apresentou RA estatisticamente maior que o G1 $(2,76 \pm 0,86 \mathrm{MPa})$ e o $\mathrm{G} 4$ $(2,86 \pm 0,68 \mathrm{MPa})(\mathrm{p}<0,05)$, e não houve diferença estatística entre G2 e G3 $(2,94 \pm 0,67 \mathrm{MPa})(\mathrm{p}>0,05)$. O IAR apresentou prevalência dos escores 2 e 3 em todos os grupos. A RA do CIVMR aumenta com condicionamento com ácido fosfórico a $37 \%$ e $40 \mathrm{~s}$ de fotopolimerização, mas isto não ocorre quando o tempo de fotopolimerização é aumentado, independente do tipo de ácido utilizado; e o CIVMR apresenta prevalência de fratura na interface adesivo/bráquete.

\section{REFERENCES}

1. Buonocore MG. A simple method of increasing the adhesion of acrylic filling materials to enamel surfaces. J Dent Res 1955; 34:849-853.
2. Newman GV. Epoxy adhesives for orthodontic attachments: progress report. Am J Orthod 1965; 51:901-912.

3. Flores AR, Sáez G, Barceló F. Metallic bracket to enamel bonding with a photopolymerizable resin-reinforced glass ionomer. Am J Orthod Dentofac Orthop 1999; 16: 514-517.

4. Paschos E, Kleinschrodt T, Clementino-Luedemann T, Huth K C, Hickel R, Kunzelmann KH et al.. Effect of different bonding agents on prevention of enamel demineralization around orthodontic brackets. Am J Orthod Dentofacial Orthop 2009; 135:603-612.

5. Godoy-Bezerra J, Vieira S, Oliveira JHG, Lara F. Shear bond strength of resin-modified glass ionomer cement with saliva present and different enamel pretreatments. Angle Orthod 2006; 76:470-474.

6. Santos RL, Pithon MM, Vaitsman DS, Araújo MTS, Souza MMG, Nojima MGC. Long-Term fluoride release from resin-reinforced orthodontic cements following recharge with fluoride solution prevention of demineralization around orthodontic brackets in vitro. Braz Dent J 2010;21:98-103.

7. Bishara SE, Vonwald L, Olsen ME, Laffoon JF, Jakobsen JR. Effect of light-curing time on the initial shear bond strength of a glass ionomer adhesive. Am J Orthod Dentofac Orthop 2000; 117:164168.

8. Lin YC, Lai YL, Chen WT, Lee SY. Kinetics of fluoride release from and reuptake by orthodontic cements. Am J Orthod Dentofacial Orthop 2008; 133:427-434.

9. Fajen VB, Duncanson MG, Nanda RS, Currier F, Angolkar PV. An in vitro evaluation of bond strength of three glass ionomer cements. Am J Orthod Dentofacial Orthop 1990; 97:316-322.

10. Valente MV, Rijk WG, Drummond JL, Evans CA. Etching conditions for resin-modified glass ionomer cement for orthodontic brackets. Am J Orthod Dentofacial Orthop 2002; 121:516-520.

11. Artun J, Bergland S. Clinical trials with crystal growth etching as an alternative to acid-etch enamel pretreatment. Am J Orthod Dentofac Orthop 1984; 116:333-340.

12. Fox NA, McCabe JF, Buckley JG. A critique of bond strength testing in orthodontics. Br J Orthod 1994; 21:33-43.

13. Bishara SE, Vonwald L, Olsen ME, Laffoon JF, Jakobsen JR. Effect of altering the type of enamel conditioner on the shear bond strength of a resin-modified glass ionomer adhesive. Am J Orthod Dentofac Orthop 2000; 118:288-294.

14. Silverman E, Cohen M, Demke R, Silverman M. A new light-cured glass ionomer cement that bonds brackets to teeth without etching in the presence of saliva. Am J Orthod Dentofacial Orthop 1995; 108:231-236.

15. Hitmi L, Muller C, Muajajic M, Attal JP. An 18-month clinical study of bond failures with resin-modified glass ionomer cement in orthodontic practice. Am J Orthod Dentofacial Orthop 2001; 120:406-415.

16. Nakamishi I, Iwaku M, Fusayama T. Bovine teeth as possible substitutes in the adhesion test. J Dent Res 1983; 62:1076-1081.

17. Lopes MB, Sinhoreti MAC, Sobrinho LC, Consani S. Comparative study of the dental substrate used in shear bond tests. Braz Oral Res 2003; 17:171-175.

18. Reynolds IR. A review of direct orthodontic bonding. Br J Orthod $1979 ; 2: 171-178$

19. Mount GJ, Patel C, Makinson OF. Resin modified glass-ionomers: strength, cure depth and translucency. Aust Dent J 2002; 47: 339343.

20. Iazzetti G, Burgess JO, Gardiner D. Selected mechanical properties of fluoride-releasing restorative materials. Oper Dent 2001;26: 2126.

Accepted October 29, 2010 